This document is the accepted manuscript version of the following article:

Sacchi, R., \& Bauer, C. (2020). Should we neglect cement carbonation in life cycle inventory databases? International Journal of Life Cycle Assessment. https://doi .org/10.1007/s11367-020-01776-y

\title{
1 Should we neglect cement carbonation in life cycle inventory
}

\section{2 databases?}

3 Romain Sacchi ${ }^{\mathrm{a}, \mathrm{b}}$, Christian Bauer ${ }^{\mathrm{b}}$

$4 \quad{ }^{a} R \& D$, Quality and Technical Sales Support, Cementir Holding, Aalborg, Denmark

$5 \quad{ }^{b}$ Technology Assessment group, Laboratory for energy systems analysis, Paul Scherrer Institut, Villigen, Switzerland

$6 \quad *$ Corresponding author: email - romain.sacchi@psi.ch, telephone - +41767621922, fax - +41563102199

7 Word count:

$8 \quad$ Abstract

9 Purpose. This study assesses the effect of including $\mathrm{CO}_{2}$ uptake by cement-containing materials (CCM) in

10 background life cycle inventories, on comparative life cycle assessments.

11 Methods. The carbonation of CCM consumed by transforming activities in the ecoinvent database is estimated.

The uncertainties around parameters that affect cement carbonation (e.g., geometry and environment types) are approximated by error propagation. Pairwise comparisons of functionally equivalent product systems are conducted in two parallel Monte Carlo simulations to isolate the effect of cement carbonation using pre-sampled values.

Results and discussion. Based on the five comparative assessments, there is a maximum probability of $3.7 \%$ that including cement carbonation in background inventories of ecoinvent can affect end-results to the extent of changing conclusions. While a probability of $3.7 \%$ is admittedly low, this finding is exclusively based on ecoinvent inventories. Therefore, should the inventories rely on background activities that consume CCM to a larger extent, or from another database, this probability may be higher.

Conclusions. It is difficult to state whether including cement carbonation in background inventories is likely to significantly change the outcome of a comparative study. It seems though that neglecting cement carbonation in background inventories currently creates, at best, a mild bias in favor of CCM-poor product systems. Given the clear and easy-to-implement method presented in this study, the authors recommend including cement carbonation in the future development of life cycle inventory databases.

Keywords: cement, concrete, carbonation, life cycle assessment, inventories, database, pre-sample, Monte Carlo. 
Romain Sacchi, the first author of this study, was employed by Aalborg Portland A/S when this study was initiated.

Aalborg Portland A/S produces Portland cement, the binding ingredient in concrete, subject to the carbonation process described in the study. While the cement industry has a clear interest in including carbonation in life cycle assessment studies of cement-containing products, the calculations performed in this study have a rigorous scientific basis and all critical assumptions are clearly stated.

Christian Bauer, from the Technology Assessment group located at the Paul Scherrer Institute, has provided continuous support and review to the manuscript.

35

\section{Introduction}

With an accumulated 4.5 Gt of carbon sequestered between 1930 and 2013, the carbonation of cement - a chemical process where the material fixes carbon dioxide $\left(\mathrm{CO}_{2}\right)$ over time - is probably the largest fabricated carbon sink in the world. In 2013 alone, cement carbonation led to the annual capture of 0.25 Gt of carbon, which is $2.5 \%$ of the amount released globally by industrial processes and the combustion of fossil fuel that same year (Xi et al. 2016). While the benefit of biomass growth on the atmospheric carbon stock is largely recognized in sustainability assessment tools like life cycle assessment (LCA) (Rabl et al. 2007), it is not necessarily so for cement carbonation (Peñaloza et al. 2018). Logically, this can lead to an overestimation of the $\mathrm{CO}_{2}$ footprint assessment of cement-intensive product systems.

Initially, cement is produced by means of calcination, a process that occurs when limestone $\left(\mathrm{CaCO}_{3}\right)$ is exposed to a temperature of around $1,450^{\circ} \mathrm{C}$ to produce clinker cement, leading to the production of calcium oxide $(\mathrm{CaO})$ and carbon dioxide $\left(\mathrm{CO}_{2}\right)$ - see Equation (1. Global cement production statistics show that calcination emissions represent about half of the total $\mathrm{CO}_{2}$ emissions per unit mass of clinker cement produced (WBCSD 2019). The other major source of $\mathrm{CO}_{2}$ during that process, left out of the scope of this study, is the combustion of fuels to reach the required temperature in the clinker kiln. The process of cement carbonation is the reverse reaction to that of calcination and leads to the sequestration of $\mathrm{CO}_{2}$ over time. It results from the hydration of $\mathrm{CaO}$ contained in the cement that produces calcium hydroxide $\left(\mathrm{Ca}(\mathrm{OH})_{2}\right)$, also called portlandite - see Equation ( 2 - which bonds in time with the $\mathrm{CO}_{2}$ present in ambient air to form $\mathrm{CaCO}_{3}$ and water $\left(\mathrm{H}_{2} \mathrm{O}\right)-$ see Equation $(3$.

$$
\mathrm{CaCO}_{3}+\mathrm{Heat} \rightarrow \mathrm{CaO}+\mathrm{CO}_{2}
$$




$$
\begin{gathered}
\mathrm{CaO}+\mathrm{H}_{2} \mathrm{O} \rightarrow \mathrm{Ca}(\mathrm{OH})_{2} \\
\mathrm{Ca}(\mathrm{OH})_{2}+\mathrm{CO}_{2} \rightarrow \mathrm{CaCO}_{3}+\mathrm{H}_{2} \mathrm{O}
\end{gathered}
$$

The carbon cycle of cement differs from that of biomass in two aspects. First, for wood products, the cycle is inverted since $\mathrm{CO}_{2}$ is absorbed during growth and released during combustion or decomposition after disposal (Houghton 1991). Second, the carbon cycle of biomass can complete within a human life span and is not deem to contribute to the long-term increase of the radiative forcing of the atmosphere - although the contribution of delayed emissions and direct and indirect land use change on the depletion of terrestrial pools of carbon is increasingly documented, as summarized by Hjuler and Hansen (2018). The carbon cycle of cement involves, on the other hand, the release of carbon previously stored as limestone for hundreds of millions of years,

affecting the long-term concentration of carbon dioxide in the atmosphere. This distinction leads to treat the $\mathrm{CO}_{2}$ exchanges during the biomass life cycle as biogenic, while they are considered of fossil nature in the case of the cement life cycle.

Based on measurements detailed in (Lagerblad 2005), temperature, relative humidity, porosity of the material as well as the availability of $\mathrm{CO}_{2}$ in the surrounding environment govern the rate the cement contained in readymix concrete, concrete elements, mortar and cement-products carbonate. This study refers to these materials as cement-containing materials $(\mathrm{CCM})$. The amount of $\mathrm{Ca}(\mathrm{OH})_{2}$ available in $\mathrm{CCM}$, the ratio between surface and volume as well as the period over which the phenomenon is considered, define the extent of carbonation.

Considering a perfectly hydrated cement paste over an infinite time horizon, the entirety of the $\mathrm{CO}_{2}$ emitted during calcination is eventually re-absorbed. In practice, these ideal conditions are never satisfied. For example, not all the $\mathrm{CaO}$ contained in the cement paste hydrates to become $\mathrm{Ca}(\mathrm{OH})_{2}$, as lumps of un-hydrated cement may form during mixing. Also, part of the $\mathrm{Ca}(\mathrm{OH})_{2}$ that precipitates into limestone may permanently stop $\mathrm{CO}_{2}$ ingress and prevent further carbonation. For these two reasons, Lagerblad (2005) assumes that a maximum of $75 \%$ of the $\mathrm{CaO}$ available in the $\mathrm{CCM}$ would react with $\mathrm{H}_{2} \mathrm{O}$ to become $\mathrm{Ca}(\mathrm{OH})_{2}$. Finally, an infinite time horizon is surely not adequate when informing decisions that have an impact on pressing environmental issues (Levasseur et al. 2016), such as that of climate change in light of the peak warming objectives set by the Paris agreement (United Nations 2016). In any case, as the rate of carbonation can be fairly approximated by the square root of time (Lagerblad 2005), most of the carbonation occur shortly after hydration: over an observation period of 100 years, half of the $\mathrm{CO}_{2}$ that can be absorbed in that period is theoretically absorbed within $\left(\frac{1}{2} * \sqrt{100}\right)^{2}=25$ years. 
Studies conducted at a national scale in Sweden (Andersson et al. 2013), Norway (Engelsen and Justnes 2013), the Netherlands (Vermeulen 2017), Ireland (Fitzpatrick et al. 2015), Denmark (Pade and Guimaraes 2007), Iceland (Pade and Guimaraes 2007) and Switzerland (Nygaard and Leemann 2012) show that between 16 and $57 \%$ of the $\mathrm{CO}_{2}$ emitted during the calcination of limestone is eventually re-absorbed during the life cycle of cement-containing products. These studies stress that further $\mathrm{CO}_{2}$ is absorbed when the $\mathrm{CCM}$ undergo extensive crushing into finer fractions, as it considerably increases its surface-to-volume ratio and favors carbonation. A study from 2016 (Xi et al. 2016) based on the world cement production between 1930 and 2013 estimates that $43 \%$ of the $\mathrm{CO}_{2}$ emitted from calcination during that period has been absorbed. The importance of cement carbonation is so that the authors believe it may potentially change the conclusions of comparative studies. For example, Collins (2010) as well as García-Segura et al. (2014) agree that including carbonation in a carbon footprint comparison between natural and recycled aggregates is likely to change the conclusion in favor of the latter, provided enough atmospheric exposure is given to guarantee a complete carbonation.

Since carbonation occurs during the use, disposal and reuse phases of CCM, LCA is a particularly fitting tool to consider such atmospheric exchanges. Several LCA studies demonstrated the importance of including carbonation for CCM during the use and disposal phases. Garcia-Segura et al. (2014) find that a good processing of the concrete waste in the disposal phase can cut life cycle $\mathrm{CO}_{2}$ emissions by $47 \%$. Collins (2010), $\mathrm{Yu}$ and $\mathrm{Lu}$ (2012) and Lee et al. (2013) reach similar conclusions looking at a bridge, road pavement solutions and apartment buildings, respectively. For that reason, a method for estimating the carbonation of cement in CCM in LCA has been formalized in the standard EN-16757 by the European Committee for Standardization (European Committee for Standardization 2017), largely based on the existing work of Lagerblad (2005).

Yet, the process of carbonation can only be conveniently included by the LCA practitioner when cement is a major input to the foreground inventory (i.e., the part of the inventory modelled by the practitioner itself) as it requires a thorough understanding of how the CCM is used. In the background inventory (i.e., the part of the inventory provided by a secondary data source, such as a database), the precise context for cement use is often difficult to know and makes the modelling of carbonation challenging. It would require thorough knowledge on the quantity and type of cement used at the different levels of the background inventory, but also the geometry of the CCM as well as the type and length of exposure. For example, in the life cycle inventory (LCI) database ecoinvent, virtually all service and product supply chains contain cement for which carbonation is not accounted for. Some activities consume CCM directly (e.g., the ready-mix concrete consumed for the construction of a 
housing system for cattle) and others indirectly (e.g., the ready-mix concrete consumed for the underground foundation required for the provision of electricity from wind turbines) (Wernet et al. 2016).

A legitimate question, unanswered by the literature as of now, is whether the current practice of disregarding carbonation of cement in LCI databases can lead to results significantly biased toward supply chains of products or services that are less cement-intensive, as the potential $\mathrm{CO}_{2}$ uptake along the supply chain of the alternative, more intensive in cement use, is disregarded. This study tries to answer this question and indicate LCI database developers if efforts should be pursued to include cement carbonation, or if its significance on end-results would not justify such endeavor.

\section{Method}

Using the LCI database ecoinvent v.3.5 "cut-off", the objective is to incorporate the potential $\mathrm{CO}_{2}$ uptake in all the activity datasets that consume CCM and compare the environmental performance of activities with an equivalent function regarding their potential contribution to climate change. The method to calculate the potential $\mathrm{CO}_{2}$ uptake per unit of $\mathrm{CCM}$ is based on the Annex BB of the European standard EN-16757. However, a few additional steps are required to extract the necessary information from the LCI database. This section describes in detail the workflow followed, also illustrated in Figure 1.

The first step consists of building the arborescence of CCM markets - shown as step 1 in Figure 1. It allows calculating important parameters such as the clinker content per unit mass of CCM, as well as the use of supplementary cementitious materials, etc. At that point, it is possible to calculate the theoretical maximum amount of $\mathrm{CO}_{2}$ absorbed in ideal conditions, per unit mass of CCM - see step 2 in Figure 1. Since ideal conditions are unrealistic, the actual rate and extent of carbonation need to be defined as well, considering conditions of use, geometry, etc., determined by the transforming activity that consume the CCM. Metadata from transforming activities that consume CCM provide several other parameters such as the expected lifetime of the structure, the type of application, etc. - see steps 3 and 4 in Figure 1. Based on a classification of application types, corresponding computer-assisted drawings (CAD) sourced from an online repository (Trimble Inc. 2017) help to calculate probability intervals for geometry-related parameters such as surface-to-volume ratios and shares of the total surface exposed to a given type of environment (e.g., outside, underground, sheltered, etc.) - see steps 5 and 6 in Figure 1. These parameters are sufficient to obtain a probability distribution for potential $\mathrm{CO}_{2}$ uptake over time per unit of $\mathrm{CCM}$, using error propagation on uncertain parameters (mostly related to geometry and exposure type) for each of the 979 transforming activities that 

consume CCM - see step 7 in Figure 1. Pairs of functionally-equivalent activities from the ecoinvent database that do not directly consume CCM are used as proxies for "foreground" processes, and compared using a Monte Carlo analysis, with and without considering carbonation - see step 9 in Figure 1. In order to ensure that the effect of cement carbonation is correctly isolated in this comparison, a few additional steps are needed to guarantee the reproducibility and coherence of the values picked by the Monte Carlo algorithm, detailed in Section 2.5.

The code to reproduce the step-by-step implementation of the method is available in the Electronic Supplementary Material.

\subsection{Linking activities to cement and concrete markets}

The first step is to list activities that consume CCM. In the ecoinvent database, cement is consumed directly or indirectly by a transforming activity under any of the four following forms of CCM: ready-mix concrete, concrete elements (e.g., concrete blocks), mortar (i.e., the cement is directly mixed with water and sand) or cement products (e.g., fiber-reinforced cement roof tiles). These CCM inputs are linked to their corresponding supply markets, which need to be linked to the production activities until the production activities at the beginning of the supply chain are reached (i.e., production of cement clinker). Figure 2 illustrates such supply chain for concrete. Table 1 describes the number of unique concrete and cement production activities and markets.

When the arborescence is complete, it is possible to determine several indicators for any given ready-mix concrete, concrete element, mortar paste or cement product, such as the quantity and type of cement used, the clinker content, the use of other constituents (e.g., fly ash, ground granulated blast furnace slag, burnt shale), etc. For the activities that supply cement, the clinker content is found in the exchanges of the dataset. The clinker production dataset also indicates the $\mathrm{CO}_{2}$ emission associated with the calcination of limestone. This can be used to determine the maximum theoretical amount of $\mathrm{CO}_{2}$ that can be absorbed per $\mathrm{kg}$ of clinker, since under ideal conditions, the $\mathrm{CO}_{2}$ emitted during calcination can be entirely absorbed during carbonation. Alternatively, this maximum amount of $\mathrm{CO}_{2}$ uptake can also be calculated from the concentration of $\mathrm{CaO}$ in the clinker, if specified. Based on the recommended methodology of EN-16757, the maximum $\mathrm{CO}_{2}$ uptake per kilogram of cement is calculated the following way: 
With:

$$
U_{t c c}=w * C_{c} *\left(\frac{m_{\mathrm{CO}_{2}}}{m_{\mathrm{CaO}}}\right)
$$

- $\quad w$ being the $\mathrm{CaO}$ concentration in the clinker $[\mathrm{kg} \mathrm{CaO} / \mathrm{kg}$ clinker $]$,

- $\quad \mathrm{C}_{\mathrm{c}}$ being the clinker content in the cement [ $\mathrm{kg}$ clinker $/ \mathrm{kg}$ cement],

- $\mathrm{m}_{\mathrm{CO} 2}$ being the molar weight of $\mathrm{CO}_{2}$,

- $\mathrm{m}_{\mathrm{CaO}}$ being the molar weight of $\mathrm{CaO}$.

In this study, the maximum $\mathrm{CO}_{2}$ uptake per kilogram of cement is calculated with a $\mathrm{CaO}$ concentration in clinker of $65 \%$, as suggested in EN-16757. With this information, it is possible to obtain the maximum amount of $\mathrm{CO}_{2}$ a given activity can reabsorb via its direct use of $\mathrm{CCM}$.

One cannot assume this amount as definitive since the conditions of use, the characteristics of the cement paste and the geometry of the CCM, which condition the rate and extent of carbonation, have not yet been considered. This is what the next step, described in the next section, consists into.

\subsection{Lifetime, geometry and exposure}

This section details the steps needed to obtain the service time of CCM, their geometry and the type of environment they are exposed to. These parameters are needed to calculate the rate and extent of carbonation.

The lifetime of activities that consume CCM is needed in order to know the service time during which carbonation in the use phase should be evaluated for. The lifetime of the activity is usually indicated in the metadata fields of the dataset. For some of the activities, lifetime values had to be estimated from other sources or similar activities for which a value was given. Since the rate of carbonation follows the square root of time, reasonable uncertainty around the service time is not critical as most of the carbonation occurs during the first years after hydration of the cement paste.

Then, activities that consume CCM are categorized into the following application types: civil infrastructure, residential, machine, cement product, mortar and concrete element.

For each application type, the surface-to-volume ratio and environmental exposure types are defined. Surface-tovolume ratios and exposure types by surface share are difficult to find and are critical to the carbonation rate. A review of over forty computer-assisted drawing (CAD) models using CCM were reviewed using the CAD software Sketchup (Trimble Inc. 2017). The software allows to calculate the volume and surface associated to the CCM in each model. It was completed by a few examples provided by the standard EN-16757. Uncertainty intervals with lower and upper values are provided, to test the variation of these parameters on the rate of 
carbonation using error propagation. Figure 3 illustrates some of the CAD considered. Table 2 and 3 show respectively some of the surface-to-volume ratio values calculated and a summary of interval values per application type for the error propagation analysis.

Using the following equation provided by EN-16757:

where:

$$
\mathrm{CO}_{2} \text { uptake }=\left(\Sigma k_{i} * K_{k} * D_{c} * A_{i}\right) *\left(\frac{\sqrt{t}}{1000}\right) * U_{t c c} * C
$$

- $\mathrm{k}_{i}$ is a factor for the penetration rate of carbonation for an exposure type $i$, in mm/year ${ }^{0.5}$,

- $K_{k}$ is a correction factor to be used in presence of other major constituents (e.g., fly ash)

- $D_{c}$ is the degree of carbonation, in percentage,

- $A_{i}$ is the area (or surface), in $\mathrm{m}^{2}$, exposed to the exposure type $i$,

- $t$ is time, in years,

- $U_{t c c}$ is the maximum amount of $\mathrm{CO}_{2}$ that can be absorbed, based on the clinker content in the cement and associated calcination emissions,

- $\quad$ and $C$ is the cement content per unit of volume,

the error propagation analysis iterates 10,000 times over each of the 979 activities that consume CCM, to calculate the $\mathrm{CO}_{2}$ uptake during the use phase of the activity. The parameters that are left to vary within predefined intervals for each iteration are related to the geometry of the material (conditioned by the type of application) and the type of concrete (compressive strength and composition). The surface-to-volume ratios are randomly distributed following a normal distribution, while the surface share values are uniformly distributed within a minimum and maximum value. Geometry-related parameters, as well as the share of the surface exposed to each type of environment $i$ and the 28-day compressive strength of the CCM and its composition, eventually define $k_{i}, K_{k}, D_{c}$ and $A_{i}$, based on values given in the Annex BB of the standard EN-16757. $t, U_{t c c}$ and $\mathrm{C}$, while they change for each activity, are left fixed from one iteration to another.

Resulting distributions of $\mathrm{CO}_{2}$ uptake per unit of $\mathrm{CCM}$ from the error propagation analysis are characterized against commonly used parametric probability distributions. Because the Monte Carlo LCA algorithm that is used at a later stage cannot consider the dependency relation between $\mathrm{CCM}$ use and total $\mathrm{CO} 2$ uptake function of CCM use, 10,000 random values are generated by multiplying the uncertainty distribution of CCM use (given by ecoinvent) with that of $\mathrm{CO}_{2}$ uptake per unit of $\mathrm{CCM}$. These samples generated prior to the Monte Carlo simulation are called pre-samples. They are later passed to the Monte Carlo algorithm to ensure that "random" 
values picked for the total $\mathrm{CO}_{2}$ uptake, which is function of $\mathrm{CCM}$ use, are correctly paired with the "random" values picked for CCM use in order to preserve the mass balance.

\subsection{End-of-Life}

The European standard EN-16757 remains very permissive on the way to account for $\mathrm{CO}_{2}$ absorption during the crushing and storing of CCM during disposal, and that is because waste sorting practices for demolition waste may differ a lot from a country to another (Gálvez-Martos et al. 2018). It is in fact a crucial step: as the material is crushed, the surface-to-volume ratio increases substantially, thereby increasing Ai per cubic meter of CCM (see Equation (5). Yet, much depends on the way the crushed material is stored:

- underground, the carbonation will be slowed down, and $\mathrm{k}$ factors corresponding to underground conditions should be used,

- stockpiled, only the outer layer will carbonate as air is not likely the flow through the pile,

- scattered on the ground, the carbonation will occur fast.

Based on a review of several European studies, the research project on concrete carbonation led by IVL

(Stripple et al. 2018) recommends considering the uptake of $10 \mathrm{~kg} \mathrm{CO}_{2}$ per cubic meter of waste CCM. In ideal storing conditions, up to $20 \mathrm{~kg} \mathrm{CO}_{2}$ absorbed per cubic meter of waste $\mathrm{CCM}$ can be considered. Because all activities consuming $\mathrm{CCM}$ also contain a corresponding waste treatment process of an equivalent input, a negative gaseous emission of $10 \mathrm{~kg}$ of $\mathrm{CO}_{2}$ per cubic meter of $\mathrm{CCM}$ waste treated is added within the inventory of all waste treatment processes for CCM contained in the database, based on a density of 2,300 kg per cubic meter of CCM. It is to be noted that, in practice, if the concrete is extensively crushed, larger amounts of $\mathrm{CO}_{2}$ can be absorbed. Therefore, the use of $10 \mathrm{~kg}$ of $\mathrm{CO}_{2}$ per cubic meter of $\mathrm{CCM}$ waste treated should be considered conservative.

\subsection{Reuse}

In Europe, the recycling rate of construction and demolition waste reached 89\% in 2016 (Eurostat 2016). This is reflected also in ecoinvent, where some of the regional markets for CCM waste provide inputs to recycling markets for CCM. In practice, crushed concrete can be used as a substitute for natural aggregates. It is often the case for road construction, where it is used as a road base material (Gálvez-Martos et al. 2018). Given the spectrum of possible conditions for reuse, the IVL report guidelines suggest accounting for an additional $\mathrm{CO}_{2}$ uptake of $10 \mathrm{~kg}$ per cubic meter of CCM reused. Therefore, such amount is included in the market activities of the database concerned with the reuse of CCM. 

boundary set by the maximum possible $\mathrm{CO}_{2}$ uptake minus the uptake that has already occurred during the Use phase.

\subsection{Life cycle impact assessment}

Using the impact assessment method GWP100a, that contains the characterization factors defined by the IPCC with a time horizon of 100 years (IPCC 2014), and the LCA framework Brightway2 (Mutel 2017), a pairwise comparison between activities from the ecoinvent v. 3.5 "cut-off” LCI database is done using a Monte Carlo approach. The Monte Carlo function, as implemented in Brightway2, would, for a given number of iterations, replace the default amounts of product or service exchanged between activities of the database (or between activities and the biosphere, in case of a direct emission), with randomly generated numbers within a probability distribution predefined by ecoinvent and the persons responsible for generating the inventories. The function would subsequently solve the inventory for the product systems studied with these new values. Pairs of functionally equivalent activities that do not directly consume CCM are used as proxies for "foreground" product systems and are compared over 10,000 iterations in two parallel Monte Carlo simulations. In the first simulation, activities are linked to a version of the LCI database that includes carbonation, while it is excluded in the database used in the second simulation. This allows counting the number of instances where, for a same iteration, the conclusion from the first Monte Carlo simulation differs from the second. This returns the probability for cement carbonation to change the conclusion of a comparative LCA, which can be formulated as:

$\mathrm{P}\left((a<b) \neq\left(a^{\prime}<b^{\prime}\right)\right)=\frac{\text { iterations where pairwise comparison differ after including carbonation }}{\text { Total number of iterations }}$

However, to ensure that the effect of cement carbonation in this comparison is isolated, two conditions have to be satisfied:

- Pre-sampled values regarding CCM use and $\mathrm{CO}_{2}$ uptake function of $\mathrm{CCM}$ use must be passed to the Monte Carlo algorithm so that they are not picked independently from one another.

- A same seed parameter, which is a starting value for generating pseudorandom numbers, must be passed to both Monte Carlo simulations so that similar random values are picked from the technology matrix for each iteration.

As described in Section 2.2, pre-samples for $\mathrm{CO}_{2}$ uptake function of CCM use are generated by multiplying the uncertainty distribution for CCM use by the uncertainty distribution for $\mathrm{CO}_{2}$ uptake per unit of CCM. They are fitted into a Brightway2-compatible matrix format using the library presamples (Lesage and Mutel 2019). 
The activities selected deliver GWP100a impact results of the same range: it increases the likelihood to observe changes in conclusions, which can then be measured. Choosing pairs of datasets with too different GWP100a impact results will likely not lead to changes in conclusions during the Monte Carlo analysis, whether cement carbonation is considered or not. Hence, the following activities are compared:

- Comparison 1: 1 kilowatt hour of electricity, high voltage, provided by a run-of-the river hydropower plant and a hydropower plant with reservoir in Alpine conditions,

- Comparison 2: 1 cubic meter of manure slurry supplied by a facility in the region of Québec and a similar facility in Switzerland,

- Comparison 3: 1 kilogram of stored roughage for cattle, dried by cold air, against a same kilogram of stored roughage dried with solar energy, both located in Switzerland,

- Comparison 4: 1 kilogram of cathode, for aluminium electrolysis, produced in Europe and Rest-of-theWorld, respectively

- Comparison 5: the supply of 1 kilogram of bronze against 1 kilogram of brass, both supplied on the Swiss market.

These inventories are sourced directly from the ecoinvent database. While it is not guaranteed that the product systems compared align to a satisfying extent in terms of geographical and technological representativeness, as it should be ensured by any ISO 14040-compliant LCA study, efforts have been made to pick pairs of activities that seem to deliver a similar function. While they may not be strictly equivalent and likely supply different markets in practice, they are deemed equivalent enough to illustrate the purpose of this study. Finally, it is important to underline that it is not the intent of this study to make assertions on the superiority of one product or service, over the other. Additional information on those activities is available in the Supplementary Electronic Material.

\section{Results}

Two sub-sections follow. The first sub-section shows the assessment of $\mathrm{CO}_{2}$ uptake within activities that directly consume CCM, while the second sub-section presents results of the pair-wise Monte Carlo comparison between activities that do not directly consume CCM.

\subsection{Effect of cement carbonation on CCM-consuming activities}

Following the method steps 1 to 8 (the reader should refer to Figure 1) leads to characterizing the $\mathrm{CO}_{2}$ uptake per unit of CCM consumed by activities in the ecoinvent database along their service life. Figure 4 shows such $\mathrm{CO}_{2}$ uptake for four CCM-consuming activities. On the left side of that figure, the error propagation analysis 
returns the progression of $\mathrm{CO}_{2}$ uptake per unit of $\mathrm{CCM}$ function of time, based on 10,000 iterations. The plot in the middle shows the resulting distribution of the accumulated $\mathrm{CO}_{2}$ uptake per unit of $\mathrm{CCM}$ at the end of the use phase as well as the parametric distribution that fits it best. Finally, on the right side of that figure, pre-samples for the Monte Carlo simulation are generated by multiplying the distribution of the $\mathrm{CO}_{2}$ uptake per unit of $\mathrm{CCM}$ (middle plot) by the amount of CCM consumed by the transforming activity - which is given as an uncertainty distribution by ecoinvent. Such reasoning is pursued for all the 978 transforming activities in the database that directly consume CCM before proceeding to the pair-wise Monte Carlo simulations.

Comparing the global warming impact of all CCM-consuming activities after the inclusion of carbonation using the median value allows to plot the two graphs in Figure 5. The graph on the left shows the accumulative density distribution in terms of difference in GWP100a impacts after including the carbonation of cement. For example, the reader can see that only 35\% of the CCM-consuming activities have had their GWP impacts reduced by more than $1 \%$ due to cement carbonation. This figure drops to $10 \%$ for activities that have had a relative difference in GWP impacts superior to 5\%. Admittedly, the inclusion of cement carbonation using the median value only affects a small fraction of CCM-consuming activities in the database. Yet, among those affected, the inclusion of cement carbonation can reduce their GWP impacts by up to 35\%. It is the case, for example, with most of landfilling activities for inert materials - where cement is used for soil stabilization. The graph on the right of Figure 5 shows the accumulated density distribution in terms of calcination emissions eventually reabsorbed through cement carbonation. Here again, one can see that half the instances where CCM is consumed will lead to $20 \%$ or less of the calcination emissions being re-absorbed along the service life and after disposal. Only a small fraction of the cases (approximately 5\%) reaches a fraction of the calcination emissions reabsorbed above $60 \%$. When looking at the possible relations between the parameters used in the model and the resulting fraction of calcination emissions re-absorbed, the surface-to-volume ratio appears to have the highest Pearson correlation index (with $r=0.7$ ), followed by the share of the surface exposed to outside weather conditions (with $\mathrm{r}=0.65$ ), while the results do not seem significantly affected by the length of service time (with $r=0.5$ ). The effect of the correlation between the surface-to-volume ratio and the fraction of calcination emissions re-absorbed is depicted in Figure 6. Unsurprisingly, Portland cement used in concrete for applications with low surface-to-volume ratios (e.g., road infrastructures, such as a bridge) will re-absorb a lower fraction of its calcination emissions than when used to produce cement products (e.g., cement fiber tiles) or prefabricated concrete products (e.g., hollow core slabs) or directly in mortar. 
But is the potential effect on the end-results of comparative studies important enough when such activities are in the background of the product system? This is what the next sub-section demonstrates.

\subsection{Pair-wise Monte Carlo comparisons}

Before delving into the results of the comparative assessment, Figure 7 shows the distribution in terms of relative difference in GWP100a impacts after the inclusion of cement carbonation, for activities in ecoinvent that do not directly consume CCM. One can see that the effect of including cement carbonation is limited: $95 \%$ of the ecoinvent activities that do not directly consume CCM are impacted by $1 \%$ at most. The remaining 5\% are typically activities which rely to a large extent on the construction of facilities or infrastructures. For example, activities such as "operation, dried roughage store, non-ventilated", "fishmeal and fish oil plant construction and maintenance" or "fruit tree seedling production, for plating" see their GWP100a impact results reduced by $9.7,4.7 \%$ and $4 \%$ respectively.

Table 4 describes the results from the parallel Monte Carlo simulations, which compare equivalent activities that do not directly consume CCM over 10,000 iterations, with and without considering cement carbonation. The probability for cement carbonation to significantly influence comparative assessments of such nature considering uncertainty in the product systems remains limited. Indeed, the highest probability observed among the pairs of activities selected is for the comparison between the supply of electricity from hydropower plants of two different types ('run-of-river' against 'reservoir'). In such case, 370 iterations out of 10,000 (3.7\%) result in different outcomes, while everything else in their respective product systems is kept similar. This difference between the parallel comparisons can be visually represented in Figure 8. This figure shows the distribution of the difference in impacts, that is, the GWP100a impacts of 1 kilowatt hour of electricity supplied by a hydropower plant of type run-of-river subtracted by the impacts associated to the same electricity but supplied by the hydropower plant with reservoir, with and without including cement carbonation. One can see that the distribution including cement carbonation is slightly offset to the right, meaning in favor of the hydropower plant with reservoir.

It is difficult to determine precisely the origin of the difference in impacts in this comparison. Yet, based on the potential $\mathrm{CO}_{2}$ uptake per type of ecoinvent activity, activities that indirectly rely heavily on large cementcontaining infrastructures are likely to have their impacts reduced, comparatively to datasets that do not contain them - or at least, to a lesser extent. It seems to be the case here, where hydropower plants equipped with a reservoir require a larger amount of concrete. 
This is followed by the comparison of cathode production, where 280 out of 10,000 iterations (2.8\%) result in different outcomes. For the other comparisons, the probability for cement carbonation to alter the outcomes of the comparative analysis is inferior to $1 \%$.

\section{Discussion and conclusion}

It is important to remember that the results of the model seem to be driven by a couple of factors primarily: the surface-to-volume ratio as well as the share of the surface exposed to outside weather conditions. Unfortunately, these two factors are also characterized by significant uncertainty. This highlights an important area where this study can improve: the uncertainty surrounding the geometry of CCM. Time-permitting, this issue could be minimized by reviewing a larger sample of CAD models or by using more disaggregated application categories and corresponding surface-to-volume ratios (i.e., where one would apply a surface-to-volume ratio specific to the activity considered, instead of a ratio from a broader category).

Also, it is important to note that if the comparison is made between product systems that perform too differently, the number of Monte Carlo iterations where the sign flips can be zero, whether cement carbonation is considered or not. These are cases where cement carbonation simply has no chance of affecting the outcome of the comparison, even when including the uncertainty inherent to it.

Finally, the uptake of carbon dioxide associated to cement carbonation during the use and disposal of CCM would be best modeled over time, and not simply added to the emissions of CCM-consuming activities at "Year 0 ". But the static nature of most LCA tools and databases prevent such implementation. Alternatively, the method could potentially benefit from applying a discount rate to such emissions. This would reduce the importance of the uncertain uptake during the End-of-Life and Reuse phases occurring several decades later.

With such limitations described, the main finding of this study is that, based on a selection of functionallyequivalent activities from the ecoinvent database with similar GWP100a impacts, there is a small, albeit nonnull, probability that cement carbonation affects the conclusion of a comparative LCA assessment. The highest probability observed was $3.7 \%$, when comparing hydropower plants of different types.

Hence, should the LCA community neglect cement carbonation in inventory databases? The answer is "no" for three apparent reasons. First, while this figure seems low, the reader should remember that all the activities selected as proxies for "foreground" processes are activities from the ecoinvent database itself. The results described in the previous section are therefore only valid in this context. In other words, there might be cases 
where the probability for cement carbonation to alter the outcomes of a comparative study is higher than what has been observed, should the inventories of the foreground processes rely on CCM-consuming processes to a larger extent. In a general manner, the probability for cement carbonation to affect the results of a comparative study entirely depends on the extent CCM-consuming activities are required as background processes. Second, even though the inclusion of cement carbonation has a small chance of altering the outcome of a comparative study, it nevertheless corrects the difference in treatment observed so far between biomass and cement in LCI. Third, this study provides a clear and concise method which would allow its inclusion at minimal expense. For these reasons, the authors recommend the implementation of cement carbonation in LCI databases, provided the assumptions and values for sensitive parameters are clearly documented.

Finally, as shown in Figure 5 of Section 3.1, the rate of carbonation reached by the time the CCM is disposed of remains limited: half of the instances where CCM was consumed resulted in a carbonation rate of $20 \%$ only (i.e., only $20 \%$ of the $\mathrm{CO}_{2}$ emissions initially released during calcination were eventually re-absorbed), as opposed to a commonly accepted maximum value of $75 \%$. This aligns rather well with the country-specific studies reviewed in (Stripple et al. 2018), although much lower than the worldwide figure of $43 \%$ obtained in (Xi et al. 2016). With this untapped potential for $\mathrm{CO}_{2}$-uptake in mind, the method presented in this study will be used to identify and assess possible investment strategies for additional CCM waste processing, to maximize the uptake of $\mathrm{CO}_{2}$. More specifically, different strategies to optimize carbonation at the End-of-Life phase will be modeled and compared, trade-offs will be identified (i.e., when, and in which context, does the additional energy-related $\mathrm{CO}_{2}$ invested in enhancing the processing of $\mathrm{CCM}$ waste surpasses the expected additional $\mathrm{CO}_{2}$ uptake?) and the effect on the activities that consume them will be assessed.

\section{Acknowledgment}

The authors wish to thank Cementir Holding and Jesper Sand Damtoft, Director of the R\&D, Quality and Technical Sales Support branch, for financing this study. This study is also financed by the Paul Scherrer Institute.

\section{References}

Andersson R, Fridh K, Stripple H, Häglund M (2013) Calculating $\mathrm{CO}_{2}$ Uptake for Existing Concrete Structures during and after Service Life. Environ Sci Technol 47:11625-11633. https://doi.org/10.1021/es401775w

Collins F (2010) Inclusion of carbonation during the life cycle of built and recycled concrete: influence on their 
Engelsen CJ, Justnes H (2013) $\mathrm{CO}_{2}$-binding by concrete - carbonation speed, degree and binding capacity SINTEF. In: NCB International Seminar on Cement and Building Materials

European Committee for Standardization (2017) EN 16757:2017 - Sustainability of construction works Product Category Rule for concrete and concrete elements. Brussels

Eurostat (2016) Recovery rate of construction and demolition waste.

https://ec.europa.eu/eurostat/tgm/graph.do?tab=graph\&plugin=1\&language=en\&pcode=cei_wm040. Accessed 23 Jul 2019

Fitzpatrick D, Nolan E, Richardson MG (2015) Sequestration of carbon dioxide by concrete infrastructure: a preliminary investigation in Ireland. J Sustain Archit Civ Eng 10:66-77. https://doi.org/10.5755/j01.sace.10.1.8037

Gálvez-Martos J-L, Styles D, Schoenberger H, Zeschmar-Lahl B (2018) Construction and demolition waste best management practice in Europe. Resour Conserv Recycl 136:166-178. https://doi.org/10.1016/J.RESCONREC.2018.04.016

García-Segura T, Yepes V, Alcalá J (2014) Life cycle greenhouse gas emissions of blended cement concrete including carbonation and durability. Int J Life Cycle Assess 19:3-12. https://doi.org/10.1007/s11367013-0614-0

Hjuler SV, Hansen SB (2018) LCA of Biofuels and Biomaterials. In: Life Cycle Assessment. Springer International Publishing, Cham, pp 755-782

Houghton RA (1991) Biomass burning from the perspective of the global carbon cycle

IPCC (2014) Climate Change 2014: Synthesis Report. Contribution of Working Groups I, II and III to the Fifth Assessment Report of the Intergovernmental Panel on Climate Change. Core Writ Team, RK Pachauri LA Meyer 151. https://doi.org/10.1017/CBO9781107415324.004

Lagerblad B (2005) Carbon dioxide uptake during concrete life cycle - State of the art

Lee S, Park W, Lee H (2013) Life cycle CO2 assessment method for concrete using CO2 balance and suggestion to decrease LCCO2 of concrete in South-Korean apartment. Energy Build 58:93-102. https://doi.org/10.1016/J.ENBUILD.2012.11.034 
Lesage P, Mutel C (2019) presamples — presamples 0.2.5 documentation. https://presamples.readthedocs.io/en/latest/index.html. Accessed 22 Jul 2019

Levasseur A, Cavalett O, Fuglestvedt JS, et al (2016) Enhancing life cycle impact assessment from climate science: Review of recent findings and recommendations for application to LCA. Ecol Indic 71:163-174. https://doi.org/10.1016/J.ECOLIND.2016.06.049

Mutel C (2017) Brightway: An open source framework for Life Cycle Assessment. J Open Source Softw 2:236. https://doi.org/10.21105/joss.00236

Nygaard P V, Leemann A (2012) For the cemsuisse project 201106: Carbon dioxide uptake of reinforced concrete structures due to carbonation

Pade C, Guimaraes M (2007) The CO2 uptake of concrete in a 100 year perspective. Cem Concr Res 37:13481356. https://doi.org/10.1016/j.cemconres.2007.06.009

Peñaloza D, Erlandsson M, Pousette A (2018) Climate impacts from road bridges: effects of introducing concrete carbonation and biogenic carbon storage in wood. Struct Infrastruct Eng 14:56-67. https://doi.org/10.1080/15732479.2017.1327545

Rabl A, Benoist A, Dron D, et al (2007) How to account for CO2 emissions from biomass in an LCA. Int. J. Life Cycle Assess. 12:281

Stripple H, Ljungkrantz C, Gustafsson T, Andersson R (2018) CO2 uptake in cement-containing products Background and calculation models for IPCC implementation Commissioned by Cementa AB and IVL research foundation. Stockholm

Trimble Inc. (2017) 3D Warehouse. https://3dwarehouse.sketchup.com

United Nations (2016) Status of Treaties - Paris Agreement. https://treaties.un.org/Pages/ViewDetails.aspx?src=TREATY\&mtdsg_no=XXVII-7d\&chapter=27\&lang=_en\&clang=_en. Accessed 15 Aug 2018

Vermeulen E (2017) Balans tussen emissie en opname CO 2. 16-21

WBCSD (2019) Global Cement Database on CO2 and Energy Information. https://gccassociation.org/sustainability-innovation/gnr-gcca-in-numbers/. Accessed 10 Jun 2018 
Wernet G, Bauer C, Steubing B, et al (2016) The ecoinvent database version 3 (part I): overview and methodology. Int J Life Cycle Assess 21:1218-1230

Xi F, Davis SJ, Ciais P, et al (2016) Substantial global carbon uptake by cement carbonation. Nat Geosci 9:880883. https://doi.org/10.1038/ngeo2840 Environ 17:380-388. https://doi.org/10.1016/J.TRD.2012.03.004

\section{Tables}

\begin{tabular}{lc}
\hline Activities for cement production & 99 \\
\hline Cement market datasets & 52 \\
\hline Activities for concrete production & 66 \\
\hline Concrete market datasets & 43 \\
\hline Activities that consume concrete or cement & 978
\end{tabular}

Table 1 Descriptive statistics on the production and use of cement and concrete in ecoinvent v. 3.5 "cut-off"

\begin{tabular}{|c|c|c|c|c|}
\hline Description & Application type & $\begin{array}{l}\text { Surface } \\
{\left[\mathbf{m}^{2}\right]}\end{array}$ & Volume $\left[\mathrm{m}^{3}\right]$ & Surface-to-volume $\left[\mathrm{m}^{2} / \mathrm{m}^{3}\right]$ \\
\hline Concrete bridge, national road & Civil engineering structures & 10890 & 6210 & 1.8 \\
\hline Concrete bridge, national road & Civil engineering structures & 721 & 597 & 1.2 \\
\hline Concrete bridge, highway & Civil engineering structures & 1896 & 601 & 3.2 \\
\hline Precast Concrete Traffic Barrier & Concrete element & 11.6 & 1.14 & 10.1 \\
\hline Pavement block & Concrete element & $7.2 \mathrm{e}-2$ & $1.16 \mathrm{e}-3$ & 62.0 \\
\hline Pavement block & Concrete element & $8 \mathrm{e}-2$ & $1.2 \mathrm{e}-3$ & 66.7 \\
\hline Concrete building structure & Residential & 995 & 205 & 4.9 \\
\hline Typical small office & Residential & 553 & 101 & 5.5 \\
\hline Concrete building, prefabricated elements & Residential & 48 & 8 & 6.1 \\
\hline 3-storey concrete house & Residential & 4169 & 540 & 7.7 \\
\hline Prefabricated stairs & Concrete element & 22 & 1.83 & 12.0 \\
\hline Prefabricated stairs & Concrete element & 31 & 2.4 & 13.1 \\
\hline Concrete slab & Concrete element & 14 & 0.89 & 16.0 \\
\hline Concrete building, prefabricated elements & Concrete element & 14 & 0.76 & 18.1 \\
\hline Prefabricated hollow core slab & Concrete element & 20 & 0.9 & 22.0 \\
\hline Typical small office & Residential & 468 & 19.8 & 23.6 \\
\hline Prefabricated hollow core slab & Residential & 8.84 & 0.26 & 34.0 \\
\hline Cement fiber roof tile & Cement product & 0.5 & $6 e-3$ & 80.6 \\
\hline Cement fiber roof tile & Cement product & 0.34 & 0.0039 & 88.4 \\
\hline
\end{tabular}


497 (Trimble Inc. 2017)

\begin{tabular}{|c|c|c|c|c|c|c|c|c|c|c|c|c|}
\hline \multirow[b]{2}{*}{ Uncertainty parameters } & \multicolumn{2}{|c|}{ Surface-to-volume $\left[\mathrm{m}^{2} / \mathrm{m}^{3}\right]$} & \multicolumn{2}{|c|}{$\begin{array}{l}\text { Outdoor surface, } \\
\text { sheltered from } \\
\text { rain }[\%]\end{array}$} & \multicolumn{2}{|c|}{$\begin{array}{c}\text { Outdoor } \\
\text { surface, } \\
\text { exposed [\%] }\end{array}$} & \multicolumn{2}{|c|}{$\begin{array}{c}\text { Indoor } \\
\text { surface, } \\
\text { covered [\%] }\end{array}$} & \multicolumn{2}{|c|}{$\begin{array}{c}\text { Indoor } \\
\text { surface, } \\
\text { uncovered } \\
{[\%]}\end{array}$} & \multicolumn{2}{|c|}{$\begin{array}{c}\text { In ground } \\
\text { surface [\%] }\end{array}$} \\
\hline & Mean & Std. dev. & Min. & Max. & Min. & Max. & Min. & $\operatorname{Max}$ & Min. & Max. & Min. & $\operatorname{Max}$ \\
\hline Residential & 6.2 & 1.1 & 2.5 & 7.5 & 2.5 & 7.5 & 55 & 65 & 5 & 15 & 10 & 20 \\
\hline Civil infrastructure & 2.7 & 2.3 & 25 & 35 & 45 & 55 & & & & & 10 & 30 \\
\hline Machine & 7.8 & 7.4 & & & & & 45 & 55 & 45 & 55 & & \\
\hline Product & 256.8 & 214.3 & 45 & 55 & 45 & 55 & & & & & & \\
\hline Concrete blocks & 30.1 & 25.4 & & & 2.5 & 7.5 & 55 & 65 & 5 & 15 & 10 & 20 \\
\hline Mortar & 45 & 10 & 35 & 45 & 35 & 45 & & & & & 15 & 20 \\
\hline
\end{tabular}

Table 3 uncertainty intervals for geometry-related parameters used in this analysis

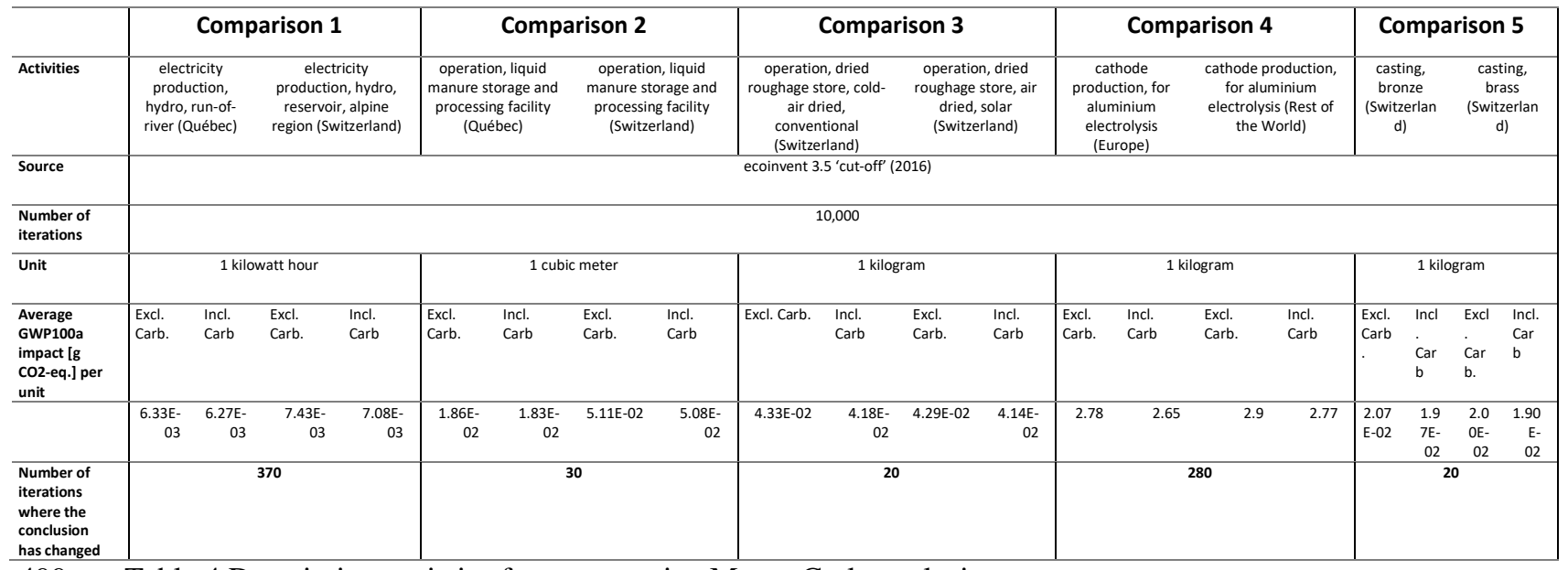

499 Table 4 Descriptive statistics for comparative Monte Carlo analysis

\section{Figure Captions}

501 Figure 1 Illustration of the method steps. Steps 1 and 2 are performed based on datasets that relate to CCM

502 production activities. Steps 3 to 8 are performed on datasets of activities that directly consume CCM. Step 9 is

503 performed on pairs of activities that do not directly consume CCM.

504 Figure 2 Relation between cement and concrete markets for a given activity

505 Figure 3 Illustration of some of the CAD models considered in this study, sourced from (Trimble Inc. 2017)

506 Figure 4 Error propagation analysis results: accumulative $\mathrm{CO}_{2}$ uptake along service time (left), accumulated

$507 \mathrm{CO}_{2}$ uptake at end of service time (middle), $\mathrm{CO}_{2}$ uptake per unit of CCM multiplied by CCM use specified by 508 ecoinvent (right) 
Figure 5 Cumulative density of difference in GWP100a impacts (left), and fraction of calcination emissions re-

510 absorbed (right) as a result of including carbonation for CCM-consuming activities

511 Figure 6 Average fraction of calcination emissions re-absorbed (left axis) and average surface-to-volume ratio

512 (right axis), per application and CCM type

513 Figure 7 Cumulative density of difference in GWP100a impacts for activities that do not consume CCM as a

514 result of including carbonation for CCM-consuming activities

515 Figure 8 Distribution of difference regarding GWP100a impacts for hydropower plants (GWP100a impacts of

516 'hydropower plant, run-of-river' subtracted by GWP100a impacts of 'hydropower plant, reservoir'), with and

517 without cement carbonation. The area under the curve to the left of the zero mark on the horizontal axis

518 indicates Monte Carlo iterations where the hydropower plant of type run-of-river performed better, and vice-

519 versa.

520 Figures

Figure 1

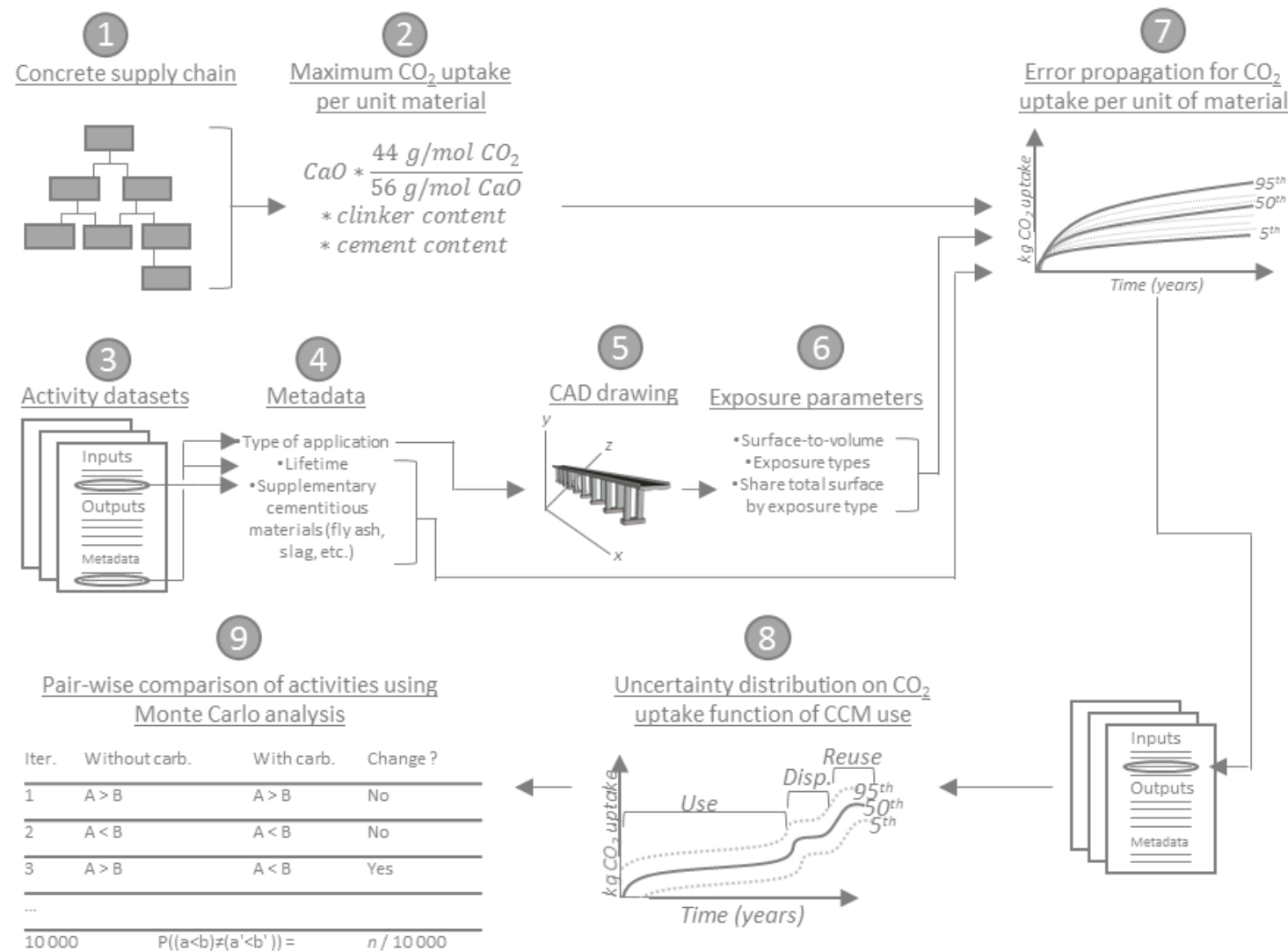




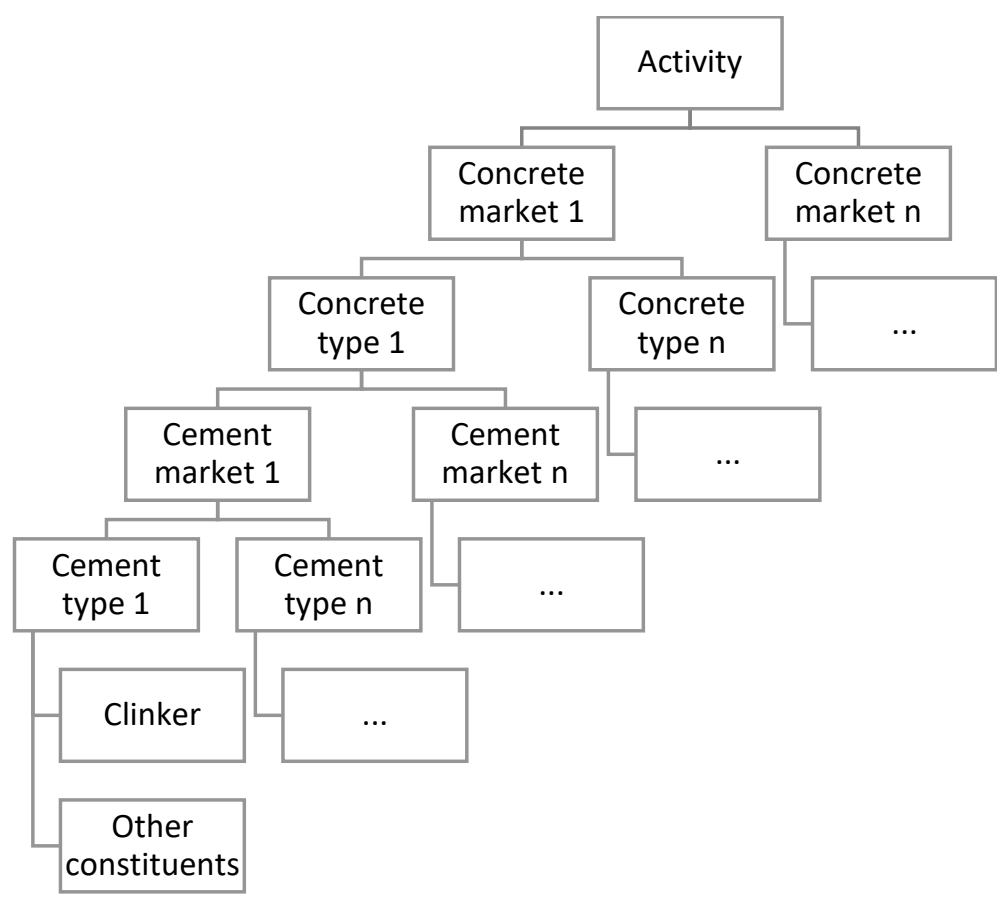

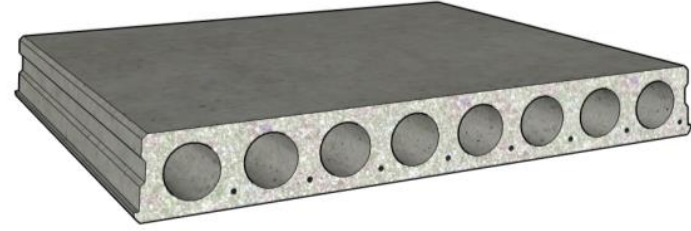

a) Concrete element example: concrete hollow-core slab

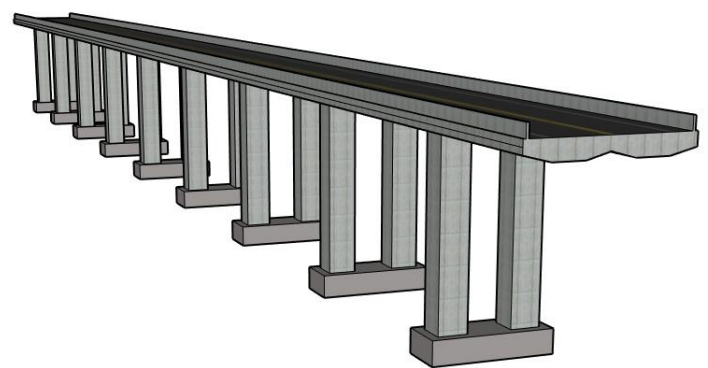

c) Civil infrastructure example: concrete bridge

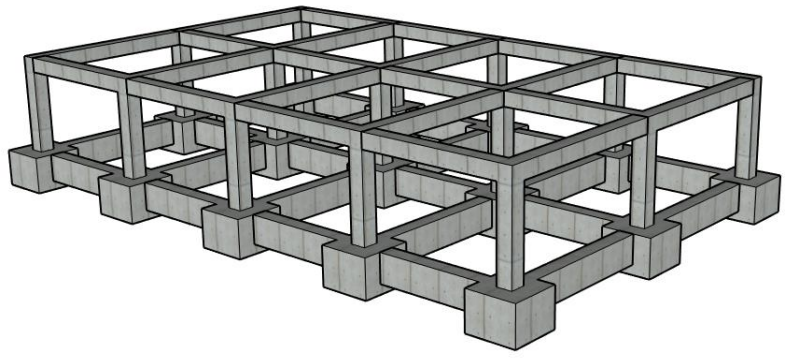

b) Residential example: concrete building structure

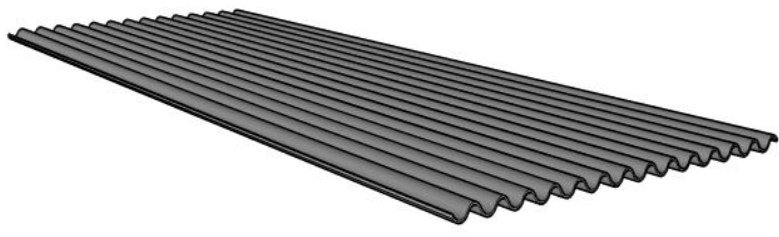

d) Cement product example: fiber-reinforced cement roof tile 


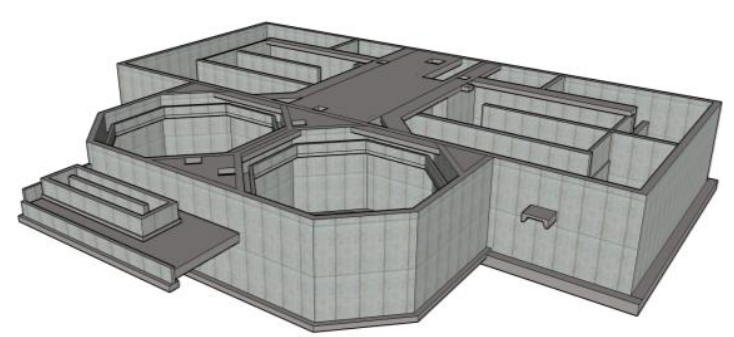

e) Civil infrastructure example: waste water treatment plant

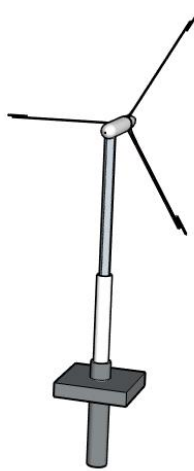

f) Machine example: foundations for wind turbines
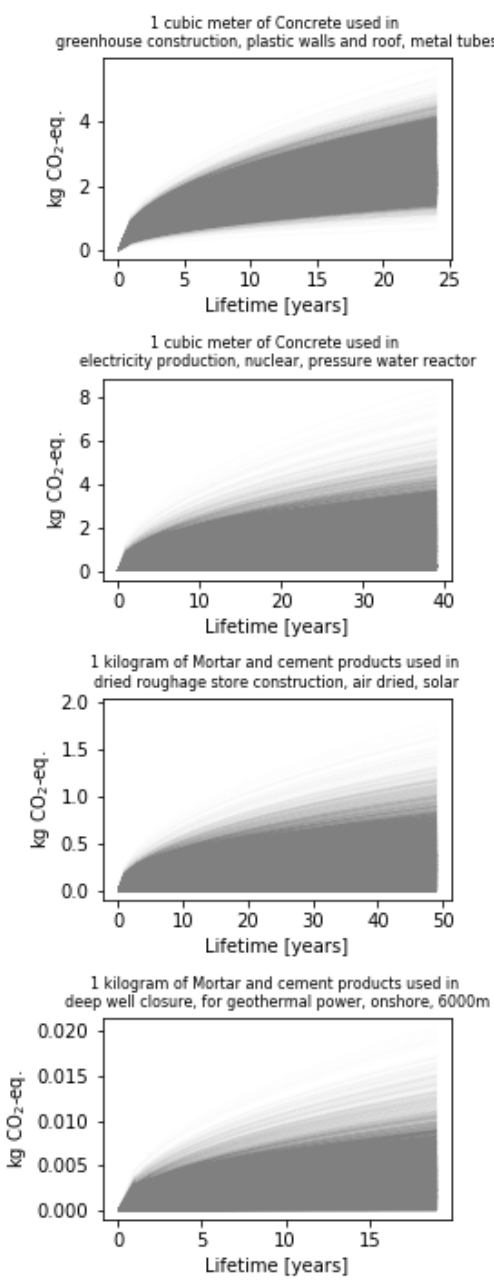
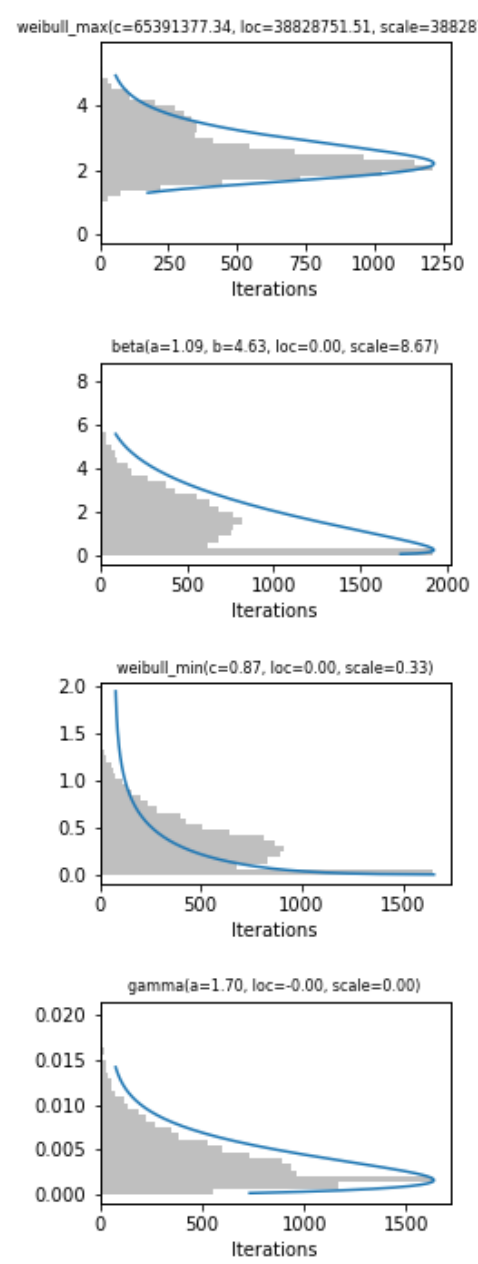
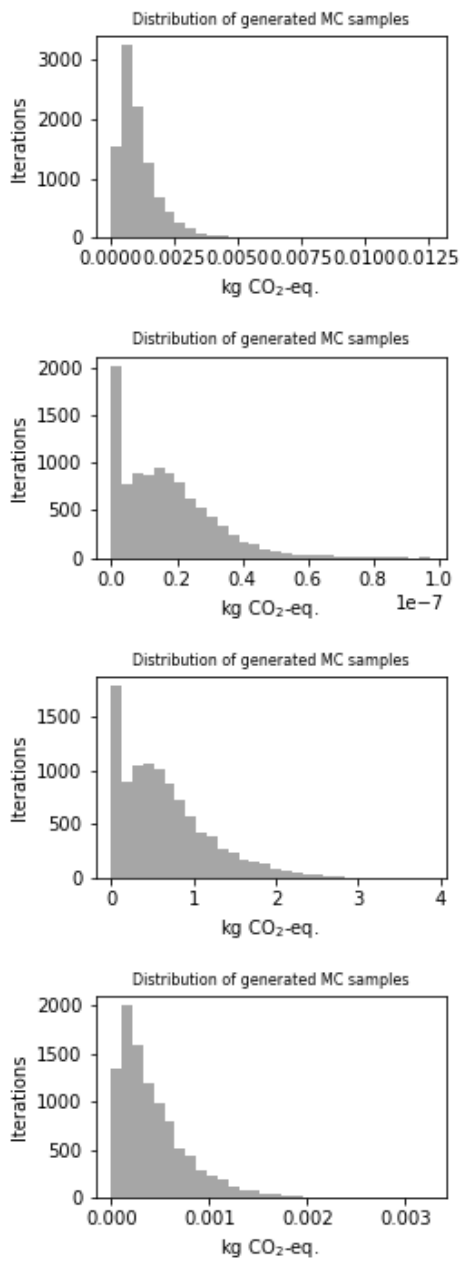

\section{Figure 5}



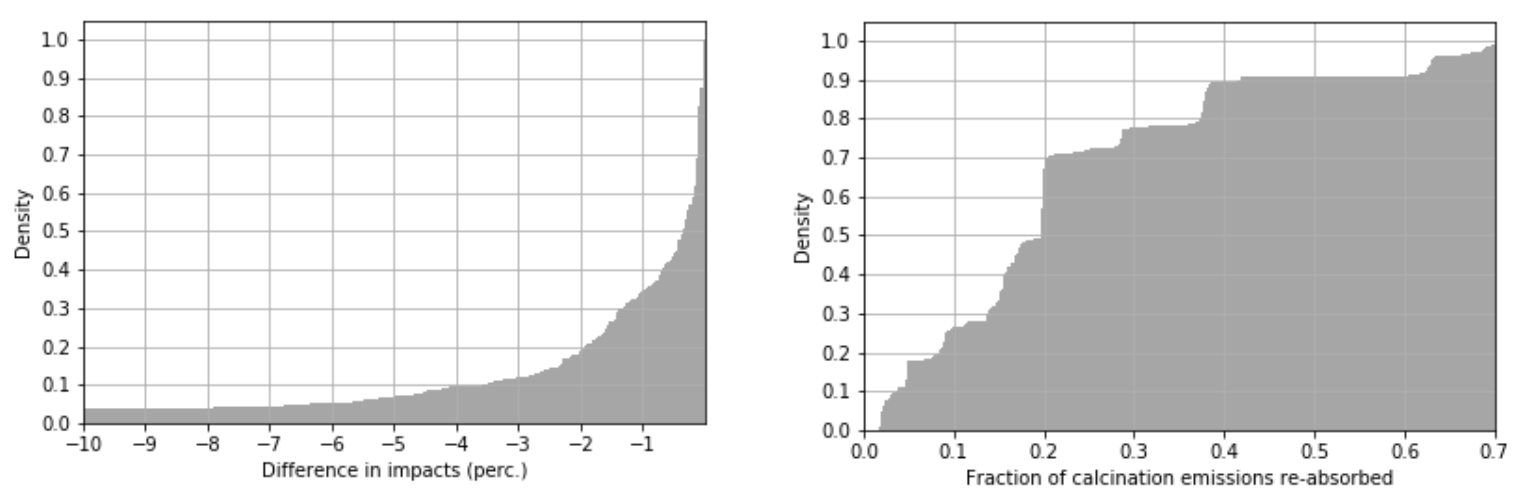

$530 \quad$ Figure 6

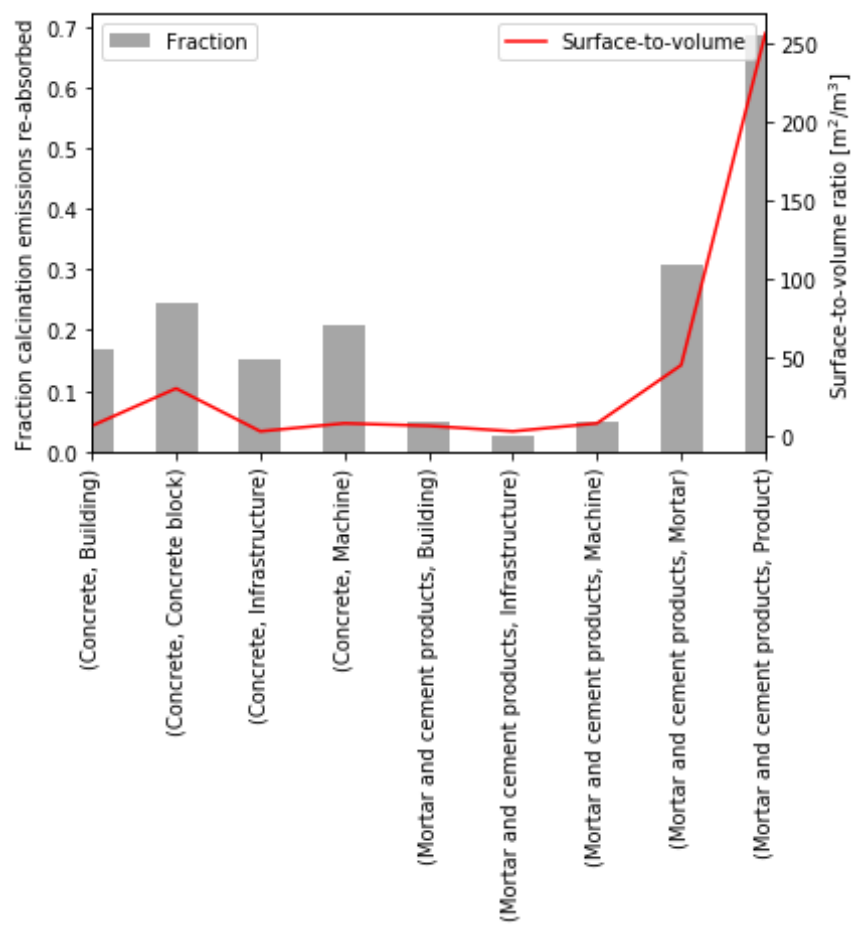

$532 \quad$ Figure 7

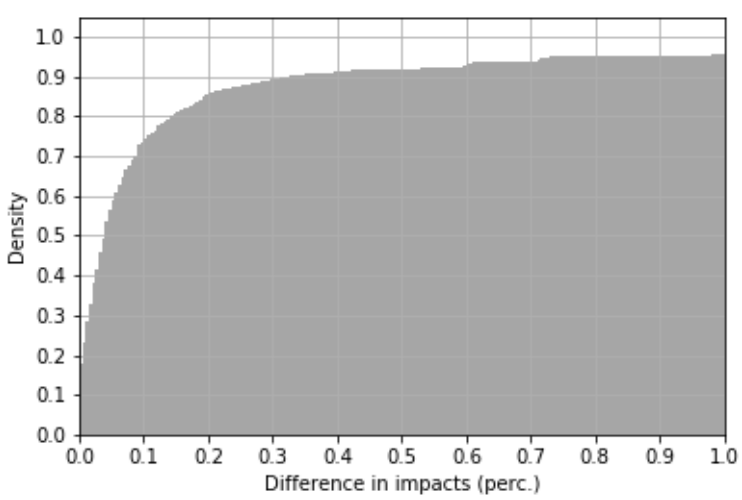

Figure 8 


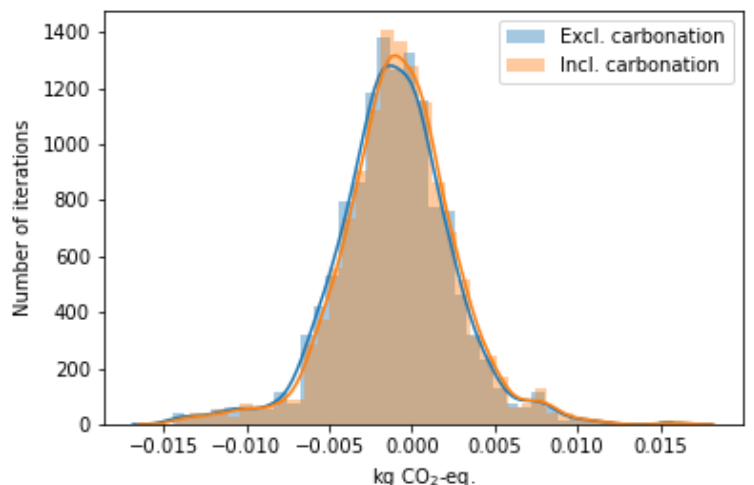

